\title{
Rumination of Music on Buddhism and Hinduism
}

\author{
Shveata Misra ${ }^{1, *}$, Ina Shastri ${ }^{2}$ \\ Department of Music, Banasthali University, Rajasthan, India \\ *Corresponding Author: shveata@yahoo.com
}

Copyright (C) 2014 Horizon Research Publishing All rights reserved.

\begin{abstract}
Universe is Naad i.e. The sound and the vibration. Universe has originated from the pattern of frequency and therefore the matters that seem firm including the emotional, physical and mental and even the spiritual realms are all through the Naad: the sound and the vibratory basis. Einstein even formulated and accepted this fact of origin of universe. According to "Einstein": "Every atom and molecule is formed out of energy vibrations'. Everything around us is musical. Music gives us the capability to express the deepest intuitive feeling of human soul. Every individual has unlike ways of evincing the inner self through different forms of habituating music. Some prefer just listening to different genres of music, other might just like to play an instrument and some prefer to meditate or chant holy hymns or sincere chants of praise, which helps in lifting up the mind to a sublime state. Music has played crucial role in spreading religious chants to a great extent especially in Hinduism and Buddhism. In Hinduism 'Om' and in Buddhism 'Om Mani Padme Hum' and 'Nam Myoh Renge Kyo' has played an awe-inspiring role in human beings life, through the mystical vibrations that generates while chanting these hymns. Further in my paper I'll be elaborating more on the reflection of music on Buddhism including the chants: Om, 'Om Mani Padme Hum' and 'Nam Myoh Renge Kyo' with brief historical background, it's effect on body and personality when chanted melodiously. There is also a strong relationship between music and health in Buddhism.
\end{abstract}

Keywords Benefits of Chants, Buddhism, Hinduism, Mystical, Nam Myoh Renge Kyo, Om, Om Mani Padme Hum, Personality, Sound, Vibrations

\section{Introduction}

Music expresses the deepest feeling of human soul, either through holy hymns or chants. Music is capable of lifting our minds to a sublime state. In Buddhism teaching of Buddha mentioned music on many occasions. As quoted in 'Amitabha Sutra' that singing and chanting is heard all day and night as flower softly rain down from the heavens. All kinds of melodious sound, present naturally become mindful of the Buddha, mindful of Dharama and that of Sangha. All
Buddhas and bodhisattvas are very skilled in utilizing music to spread Dharama and guide sentient beings to enlighten.

In one of the Buddha's teachings [Mahaprajnaparamita Sutra] it is said that:

'In order to build a Pureland, the Bodhisattvas make use of beautiful music to soften people's heart, as with their heart softened, people's mind are more receptive and thus easier to educate and transform through the teachings.'

For this reason music has been established as one type of ceremonial offering to be made to the Buddha. From its humble beginnings, Buddhist's music has developed to such an extent that it is currently performed in temples and concert halls throughout the world and can now rival the beauty of western philharmonic orchestras.

\section{Contribution of Buddhist Music to Health}

Buddhism has contributed a unique style to the world of music. Buddhist music includes esteemed and beautiful collection of gentle melodies that give praise to all the Buddhas and great Bodhisattvas. These were originally composed as expressions of the deep faith of Buddhist disciples, and by virtue of their beauty, they have left a rich legacy of superb melodies and literature. These include all kinds of gathas praising various Buddhas, such as the Bhaisajyaguru Gatha, the Avalokitesvara Gatha, as well as statements of Buddhist vows, which have contributed significantly to the broadening, enrichment, and variety of literatures. Buddhist music is characterized by a relaxed and easy pace, soft tones, and a dignified, solemn manner. It gives elegant expression to the five virtuous qualities of sincerity, elegance, clarity, depth, and equanimity. According to the Vinaya in Ten Recitations, regularly listening to Buddhist music can give the following five benefits:

1) A reduction in bodily fatigue,

2) less confusion and forgetfulness

3) A reduction in mental weariness

4) A more elegant voice, and

5) Greater ease in both personal expression and communication.

Regarding the regular practice of chanting or singing 
fanbei, A Record of the Buddhist Religions as Practiced in India and the Malay Archipelago (ch. Nanhai Ji Gui Zhuan) makes mention of six kinds of merits that can be obtained:

1. Knowledge of the depth and extent of the Buddha's virtue.

2. An intuitive realization of the truths of the Dharma.

3. A reduction in negative or harmful habits of speech.

4. A clearer and healthier respiratory system.

5. A mind freer from fear and anxiety.

6. Longevity and improved health.

Buddhist music is not designed to try to elevate or excite the emotions of participants or practitioners, but in fact aims to achieve the opposite effect. Its main functions are:

1. To conserve emotional energy,

2. Calm thoughts,

3. Reduce desire,

4. Allow practitioners to see their true nature with a clear mind.

The Flower Ornament Sutra and The Lotus Sutra contain phrases such as "conduct ceremonies and teach the Dharma with music" and "with a joyful spirit, sing the truths of the Dharma."

\section{Bhuddhist Music in Contemporary World}

The idea to modernize Buddhist Music is based on a need to respond to changes in society in order to provide the most appropriate and suitable methods to help purify the hearts and minds of the public. Indeed, the lifestyle common to most people today is very busy and quite stressful, and with many people seeming to have no place to take any kind of spiritual refuge it can often become quite easy for them to lose themselves.

Buddhist melodies are characterized as being strong, but not fierce; soft, but not weak; pure, but not dry; still, but not sluggish, and able to help purify the hearts of listeners. Through using music to perform the task of spreading the Dharma and saving sentient beings, we can reach the most remote places and overcome the limitations of time and distance, as well as differences in cultural backgrounds and nationalities. Music can help us achieve the task of widely propagating the Dharma and spreading the wisdom and compassionate vows of the Buddhas and Bodhisattvas across every corner of the globe.

Contemporary Buddhist Music is focused on bringing harmony into people's everyday lives, purifying people's minds, and performing the function of educating and transforming listeners so as to bring their emotions in line with the teachings of the Dharma. With modern media and information equipment constantly improving, we need to make full use of technology to find more efficient means to give Buddhist Music public coverage, such as through the use of electronic broadcasting media including television and radio stations. We need to use music to break through the barriers of differences in cultural backgrounds, social customs, and languages. By using all sorts of equipment such as classical instruments, laser disks, electronic organs, the piano, and many other kinds of musical implements we can create and distribute music that can suit the tastes and meet the needs of people from around the world.

\section{Psychology of Buddhist Music}

Psychologist Freud have lumped Buddhism with all of the theosophical rest. The psychoanalysis towards Buddhism can be seen in the title of psychoanalysts franz. Alexander's paper "Buddhistic Training As an Artificial Catatonia[9].

According to the Jung's Analytical Psychology 1968 - he did not seem to appreciate that Buddhism is not the same in Tibet as India, in China as Tibet, in Japan as China that is Buddhism adapts itself to the culture at least as much as individuals adapt themselves to Buddhism[2].

Buddhism as a religion is distinguished by faith in the three treasures:

a. The Buddha,

b. The Dharma (Law -natural, spiritual, and teachings),

c. The Sangha (originally community of monks, but more generally the Buddhist religious community).

The Buddhism religion contains beliefs in supernatural phenomenon such as rebirth and entities (such as devas and demons and their associated realms) which could be entertained by empirical science. These beliefs do have some influence in the psychology and philosophy of Buddhism cosmology in order to attain full liberation (1993, p.128).

Psychologists from Freud to the present times, a great deal of importance have been attached to the development through childhood. This is a period when infants develop into a person. In Buddhism greater importance is placed in death (esp. [2]). Actually this is an area where it is difficult to separate the psychology from the religion. A concept like tabula rasa is totally unthinkable in Buddhist Context since each child is born with an accumulation of kama which will have profound effect on their development.

In Buddhism psychology there is no concern with mind body, nature/nurture sorts of dichotomies. There is a distinction made between biological, situational and psychological states, but they are viewed more holistically [9].

Buddhism is an atheistic religion, something of an anomaly kind. There is no God. A distinction may be made here between the early Pali Canon and Abhidhamma and later more elaborated Buddhisms were Buddha, is a God like being, where chanting the name of Bodhisatva of Compassion will assure one rebirth into a deva realm. However in these Buddha is a supernatural teacher not a mighty creator, God, and Supreme Judge.

To phrase Buddhism in more psychological terms: there is no 'self' - Soul.

Buddhism has strong concern with ethics. While there is an emphasis on altruistic behavior in Buddhism, ethical conduct is also critical for personality development and well 
being. One of the keys to the experimental understanding of Buddhism is meditation. Buddhist psychology is very phenomenological, concerned with the inner experience of the individual, as opposed to mainstream academic.

\section{Mantra or Hymns}

The word Mantra or hymns means something that 'protects the mind'. Mantras originated from Hinduism and Buddhism. In the mainstream Buddhist and Hindu practices, mantras were and are still considered as the most essential practice in attaining spiritual advancement and enlightenment. Till date, every ritual practiced in the Hindu or the Buddhist culture is based on mantras, as they are believed to bring positivity, strength, spirituality and wealth too. Mantras often contain syllables like Om, Ah, and Hum (approximately pronounced Hoong), which have no literal meaning. There are various "understandings" or interpretations of what these might mean, and the three syllables have been correlated with body, speech, and mind respectively; or the Dharmakaya, Sambhogakaya, and Nirmanakaya respectively. It is also believed that, during the Vedic period, mantras were used by the humans to influence Gods, to get their wishes granted. Mantras are sounds that can create vibrations and can evoke the subconscious mind and spiritual forces. Mantras or hymns are commonly used in the form of a short prayer or for meditation by repeating a mantra several times. Mantras are recited either in a melodious tune or in a heavy tone holding a particular rhythm and pitch. So, the effect of the mantra lies in the placement of words and giving right-stress on different syllables in the words used in a mantra. Mantras are ideally to be chanted 108 times as per the Hindu specifications. This is because by the time you recite the mantra 108 times you reach a stage where your mind goes beyond all the worldly matters and that's when you can attain spiritual knowledge. It is also associated with the calculation that there are 12 months in a year with 12 different zodiac signs and there are 9 planets ruling them. Therefore, $9 * 12=108$ and hence a mantra is chanted 108 times. Many priests chant mantras even 1000 times while performing their pastoral duties.

Every word that we say produces a vibration and affects our physical and mental well-being. These vibrations are also sent out to the universe. Therefore, the belief that temples/ churches have a positive energy is based on the fact that, these places have positive vibrations because a lot of prayers and mantras have been and are still recited there, by thousands of people. Mantras create vibrations that are helpful for spiritual healing and increasing energy. Every mantra has a different purpose and a different positive effect on an individual. There are mantras for protection against the evil, for prosperity, for knowledge and also for gaining love.

How mantras can help you, can be understood by observing how listening to different music styles affects a person's well-being. Say for example, Beethoven's and Mozart's music is said to increase concentration, positivity and improve performance at work or in education. On the other hand, when we listen to Death metal music, it makes you hyper, restless and wild. It certainly does not calm you down or relax you or even put you at peace. This comparison is done to look at the broader view, to understand and experience how different vibrations can affect one's mental state. It is rare that a person who loves heavy metal also loves classical music. Therefore, you can then see the influence of the music one listens to, in the way they dress and talk. Further we will discuss the meaning and effects of Aum, Nam Myoho Renge Kyo and Om Mani Padme Hum on human body.

\section{Aum in Buddhism}

Aum in Buddhism is used in Mantras and Dharanis. Om is spoken at the beginning and the end of Hindu mantras, prayers, and meditations and is frequently used in Buddhist and Jain rituals as well. Om (also spelled Aum) is a Hindu sacred sound that is considered the greatest of all mantras. The syllable Aum is composed of the three sounds a-u-m (in Sanskrit, the vowels a and u combine to become o) and the symbol's threefold nature is central to its meaning. It represents several important triads:

a. the three worlds - earth, atmosphere, and heaven

b. the three major Hindu gods - Brahma, Vishnu, and

Siva

c. the three sacred Vedic scriptures - Rg, Yajur, and Sama

The symbol of AUM consists of three curves (curves 1,2, and 3), one semicircle (curve 4), and a dot. The large lower curve 1 symbolizes the waking state (jagrat), in this state the consciousness is turned outwards through the gates of the senses. The larger size signifies that this is the most common ('majority') state of the human consciousness.

The upper curve 2 denotes the state of deep sleep (sushupti) or the unconscious state. This is a state where the sleeper desires nothing nor beholds any dream.

The middle curve 3 (which lies between deep sleep and the waking state) signifies the dream state (swapna). In this state the consciousness of the individual is turned inwards, and the dreaming self beholds an enthralling view of the world behind the lids of the eyes.

These are the three states of an individual's consciousness, and since Indian mystic thought believes the entire manifested reality to spring from this consciousness, these three curves therefore represent the entire physical phenomenon.

The dot signifies the fourth state of consciousness, known in Sanskrit as turiya. In this state the consciousness looks neither outwards nor inwards, nor the two together. It signifies the coming to rest of all differentiated, relative existence. This utterly quiet, peaceful and blissful state is the ultimate aim of all spiritual activity. This Absolute (non-relative) state illuminates the other three states.

Finally, the semi circle symbolizes maya and separates the dot from the other three curves. Thus it is the illusion of 
maya that prevents us from the realization of this highest state of bliss.

The semi circle is open at the top, and when ideally drawn does not touch the dot. This means that this highest state is not affected by maya. Maya only affects the manifested phenomenon. This effect is that of preventing the seeker from reaching his ultimate goal, the realization of the One, all-pervading, unmanifest absolute principle. In this manner, the form of OM represents the unmanifest and the manifest, the noumenon and the phenomenon.

As a sacred sound also, the pronunciation of the three-syllabled AUM is open to a rich logical analysis. The first alphabet $\mathrm{A}$ is regarded as the primal sound, independent of cultural contexts. It is produced at the back of the open mouth, and is therefore said to include, and to be included in, every other sound produced by the human vocal organs. Indeed A is the first letter of the Sanskrit alphabet.

The open mouth of A moves toward the closure of $\mathrm{M}$. Between is $U$, formed of the openness of A but shaped by the closing lips. Here it must be recalled that as interpreted in relation to the three curves, the three syllables making up AUM are susceptible to the same metaphorical decipherment. The dream state (symbolized by $\mathrm{U}$ ), lies between the waking state (A) and the state of deep sleep (M). Indeed a dream is but the compound of the consciousness of waking life shaped by the unconsciousness of sleep.

AUM thus also encompasses within itself the complete alphabet, since its utterance proceeds from the back of the mouth (A), travelling in between (U), and finally reaching the lips (M). Now all alphabets can be classified under various heads depending upon the area of the mouth from which they are uttered. The two ends between which the complete alphabet oscillates are the back of the mouth to the lips; both embraced in the simple act of uttering of AUM.

The last part of the sound AUM (the M) known as ma or makar, when pronounced makes the lips close. This is like locking the door to the outside world and instead reaching deep inside our own selves, in search for the Ultimate truth.

But over and above the threefold nature of $\mathrm{OM}$ as a sacred sound is the invisible fourth dimension which cannot be distinguished by our sense organs restricted as they are to material observations. This fourth state is the unutterable, soundless silence that follows the uttering of OM. Quieting down of all the differentiated manifestations, i.e. a peaceful-blissful and non-dual state. Indeed this is the state symbolized by the dot in the traditional iconography of AUM.

The threefold symbolism of OM is comprehensible to the most 'ordinary' of us humans, realizable both on the intuitive and objective level. This is responsible for its widespread popularity and acceptance. That this symbolism extends over the entire spectrum of the manifested universe makes it a veritable fount of spirituality. Some of these symbolic equivalents are:

1) Colors: Red, White, and Black.

2) Seasons: Spring, summer, and winter.
3) Periods: Morning, Midday, and Evening.

4) States: Waking-consciousness (jagriti), Dream (svapna), and deep-sleep (sushupti).

5) Spheres: Earthly, Heavenly, and Intermediary.

6) Poetic Meters: Gayatri (24 syllables), Trishtubh (44 syllables), and Jagati (48 syllables).

7) Veda: Rigveda (knowledge of the meters), Yajurveda (knowledge of contents), Samaveda (knowledge of extension).

8) Elemental Deity: Fire (Agni), Sun (Aditya), Wind (Vayu).

9) Manifestation of Speech: Voice (vak), Mind (manas), Breath (prana).

10) Priestly Function: Making offering, Performing ritual, and Singing.

11) Tendencies: Revolving, Cohesive, and Disintegrating.

12) Quality: Energy (rajas), Purity (sattva), and Ignorance (tamas).

13) Ritual fire: Of the home, of the Ancestors, and of Invocation.

14) Goddess: Amba, Ambika, and Ambalika.

15) Gods: Of the elements (Vasus), of the sky (Adityas), of the sphere-of-space (Rudras).

16) Deity: Brahma, Vishnu, Shiva.

17) Action: Creation, Preservation, and Destruction.

18) Power: of Action (kriya), of Knowledge (jnana), and of Will (iccha).

19) Man: Body, Soul, and Spirit.

20) Time: Past, Present, and Future.

21) Stages of Existence: Birth, Life, and Death.

22) Phases of the Moon: Waxing, Full, and Waning.

23) Godhead: Father, Mother, and Son.

24) Alchemy: Sulphur, Quicksilver, and Salt.

25) Buddhism: the Buddha, Dharma, and Sangha (three jewels of Buddhism).

26) Qabalism: Male, Female, and the Uniting intelligence.

27) Japanese Thought: Mirror, Sword, and Jewel.

28) Divine Attributes: Truth, Courage, and Compassion.

According to Indian spiritual sciences, God first created sound, and from these sound frequencies came the phenomenal world. Our total existence is constituted of these primal sounds, which give rise to mantras when organized by a desire to communicate, manifest, invoke or materialize. Matter itself is said to have proceeded from sound and OM is said to be the most sacred of all sounds. It is the syllable which preceded the universe and from which the gods were created. It is the "root" syllable (mula mantra), the cosmic vibration that holds together the atoms of the world and heavens. Indeed the Upanishads say that AUM is god in the 
form of sound. Thus $\mathrm{OM}$ is the first part of the most important mantras in both Buddhism and Hinduism, e.g. Om Namoh Shivai and Om Mani Padme Hum.

\section{Nam Myoho Renge Kyo and Om Mani Padme Hum}

In Buddhism Nam Myoho Renge Kyo and Om Mani Padme hum are amongst the important mantaras of Buddhism. Let's see the brief details of above mentioned mantaras:

\subsection{Nam Myoho Renge Kyo}

Nichiren (1222-82) established the chanting of Nam-myoho-renge-kyo as the way to awaken one's Buddha nature and tap into the deepest levels of our existence, on which our own lives and that of the universe are one. He first taught the invocation of the phrase to a small group at Seicho-ji temple in Awa province, Japan, on April 28, 1253.

Myoho-renge-kyo is the name of the Lotus Sutra in Japanese pronunciation of classical Chinese characters, and so the literal meaning of Nam-myoho-renge-kyo is "I devote myself to the Lotus Sutra." As the following explanation shows, there are deeper levels of meaning attached to each element of the phrase.

\subsubsection{Nam}

Nam derives from the Sanskrit word namu, meaning "to devote oneself." Nichiren established the practice of chanting Nam-myoho-renge-kyo as a means to enable all people to put their lives in harmony or rhythm with the law of life, or Dharma. In the original Sanskrit, namu indicates the elements of action and attitude, and refers therefore to the correct action one needs to take and the attitude one needs to develop in order to attain Buddha hood in this lifetime.

\subsubsection{Myoho}

Myoho literally means the Mystic Law--the underlying truth or principle which governs the mysterious workings of the universe and our life from moment to moment. Myo refers to the very essence of life, which is "invisible" and beyond intellectual understanding. This essence always expresses itself in a tangible form (ho) that can be apprehended by the senses. Phenomena (ho) are changeable, but pervading all such phenomena is a constant reality known as myo. Myo also means to open, to revive, and to be fully endowed with the qualities we need to develop our lives.

\subsubsection{Renge}

Renge means lotus flower. The lotus blooms and produces seeds at the same time, and thus represents the simultaneity of cause and effect. The circumstances and quality of our individual lives are determined by the causes and effects, both good and bad, that we accumulate (through our thoughts, words and actions) at each moment. This is called our "karma." The law of cause and effect affirms that we each have personal responsibility for our own destiny. We create our destiny and we have the power to change it. The most powerful positive cause we can make is to chant Nam-myoho-renge-kyo; the effect of Buddha hood is simultaneously created in the depths of our life and will definitely manifest in time.

The lotus flower grows and blooms in a muddy pond, and yet remains pristine and free from any defilement, symbolizing the emergence of Buddha hood from within the life of an ordinary person in the midst of the struggles of day-to-day existence.

\subsubsection{Kyo}

Kyo literally means sutra, the voice or teaching of a Buddha. In this sense, it also means sound, rhythm or vibration. In a broad sense, kyo conveys the concept that all things in the universe are a manifestation of the Mystic Law.

\subsection{Om Mani Padme Hum}

Buddhists believe that saying the mantra (prayer), Om Mani Padme Hum, out loud or silently to oneself, invokes the powerful benevolent attention and blessings and the embodiment of compassion. It is said that all the teachings of the Buddha are contained in this mantra: Om Mani Padme Hum cannot really be translated into a simple phrase or sentence. The Mani mantra is the most widely used of all Buddhist mantras, and opens to anyone who feels inspired to practice it -- it does not require prior initiation by a lama (meditation master).

The six syllables of the mantra, as it is often pronounced by Tibetans -- Om Mani Padme Hum -- are here written in the Tibetan alphabet:

Reading from left to right the syllables are:

$$
\begin{array}{cccccc}
\underset{\mathrm{Om}}{(\mathrm{ohm})} & \begin{array}{c}
\mathrm{Ma} \\
(\mathrm{mah})
\end{array} & \begin{array}{c}
\mathrm{Ni} \\
\text { (nee) }
\end{array} & \begin{array}{c}
\text { Pad } \\
\text { (pahd) }
\end{array} & \begin{array}{c}
\text { Me } \\
\text { (may) }
\end{array} & \begin{array}{c}
\text { Hum } \\
\text { (hum) }
\end{array}
\end{array}
$$

\subsubsection{The Six Syllables Perfect the Six Paramitas of the Bodhisattvas}

Gen Rinpoche, in his commentary on the Meaning of said:

"The mantra Om Mani Pädme Hum is easy to say yet quite powerful, because it contains the essence of the entire teaching. When you say the first syllable $\mathrm{Om}$ it is blessed to help you achieve perfection in the practice of generosity, $M a$ helps perfect the practice of pure ethics, and $N i$ helps achieve perfection in the practice of tolerance and patience. Päd, the fourth syllable, helps to achieve perfection of perseverance, Me helps in achieve perfection in the practice of concentration, and the final sixth syllable Hum helps achieve perfection in the practice of wisdom.

So in this way recitation of the mantra helps achieve perfection in the six practices from generosity to wisdom. The path of these six perfections is the path walked by all the 
Buddhas of the three times.

\subsubsection{The Six Syllables Purify the Six Realms of Existence in Suffering}

For example, the syllable $O m$ purifies the neurotic attachment to bliss and pride, which afflict the beings in the realm of the gods.

\begin{tabular}{|c|c|c|}
\hline$\bigcirc$ & Purifies & Samsaric Realm \\
\hline$O m$ & bliss / pride & Gods \\
\hline$M a$ & $\begin{array}{c}\text { jealousy / } \\
\text { lust for entertainment }\end{array}$ & jealous gods \\
\hline$N i$ & passion / desire & Human \\
\hline$P e$ & stupidity / prejudice & Animal \\
\hline$M e$ & $\begin{array}{c}\text { poverty / } \\
\text { possessiveness }\end{array}$ & hungry ghost \\
\hline Hung & aggression / hatred & Hell \\
\hline
\end{tabular}

\section{Psychological Obstacles in Buddhism and Hinduism}

The initial endeavor in Buddhism as well as in Hinduism is to quiet the mind and enhance detachment and objectivity. For only when the mind has stilled its perpetual ruminating and has momentarily abandoned its fascination for sensory experience can it readily become aware of the unconscious feelings and motivations which shape our thoughts, speech, and behavior. Furthermore, only with detached objectivity and its ensuing insights can we readily confront and renounce unwholesome feelings. On the other hand, we do not achieve complete calmness and detachment so long as we harbor unwholesome feelings and unconscious emotional conflicts. Thus the process is reciprocal: the more we quiet the mind, the more we gain insight and relinquishment of undesirable feelings. The more we relinquish such feelings and resolve emotional conflicts, the more we quiet the mind and approach perfect calmness, detachment, and objectivity.

The obscuring of unconscious feelings by preoccupation with thoughts and actions is demonstrated in a variety of neurotic symptoms. Most characteristic are obsessive compulsive reactions; these occur in persons who are desperately trying to repress overpowering impulses of fear, anger, lust, or guilt. In order to achieve this repression they divert nearly all their attention to some repetitious mental or physical activity, which is conducted in a compulsive, ritualistic manner. If prevented from performing their defensive rituals, they often become acutely anxious and even panic as their unconscious feelings begin to come into awareness. Less severe examples of the same defensive phenomena are seen in persons who are chronically anxious and are continuously focusing their worries on minor concerns of exaggerated importance such as unpaid bills, social commitments, and alleged physical ills. They, too, rarely relax and are forever busy with petty chores.

These neurotic symptoms are strikingly similar to an increasingly common way of life in today's society. Our ever-expanding populations with their accompanying advertising, mass entertainment, socializing, industrialization, and emphasis upon success, sensuality, and popularity have produced an environment in which we are forever bombarded with an increasing number of sensory and emotional stimuli. The opportunities for solitude and introspection have diminished to the point that now solitude is often viewed as either depressing or abnormal. This is not to assert that the majority of our citizens are involved in a frantic endeavor to escape from their inner selves. Such is no doubt the case with many, but there still remains a sizeable percentage of people who are involved in the same frenzy only because they have conformed to the social norm and have been lured into a habitual fascination for television, jazz, sports, and the countless other forms of readily-available entertainment. Such persons are not necessarily precluded from relative happiness and emotional well-being.

It is virtually impossible for a busy person with manifold worldly ambitions to suddenly and voluntarily quiet his mind to the point of removing all discursive thoughts. In a matter of minutes, if not seconds, the mediator will find himself either planning, reminiscing, or day-dreaming. Therefore, before one begins meditation, some amount of moral development and self-discipline should be achieved.

In every Buddhist country only a minority of devotees undertake regular practice. The decision to meditate rests with each individual. Many wait until their later years when moral development has progressed and family obligations have been fulfilled. On the other hand, meditation through the chants like Om, Man Myo Reng kyo Or Om Mani Padme Hum facilitates wisdom and morality and can be of benefit to the layman as well as the monk.

In addition to adjusting one's daily routine and cultivating morality and wisdom, it is often profitable to take a few minutes before each meditation to put one's mind in a receptive condition. This may be done by reflecting upon the goals and advantages of meditation by the music or mantras like Om, Man Myo Reng kyo Or Om Mani Padme Hum, or by reading or reciting some chosen passage of Buddhist literature or other appropriate writing. If drowsy, a brisk walk may relax one's mind and can also allow one to think over and mentally dispense with matters which might otherwise be distracting. Also, if one has some necessary chores to perform which can be executed quickly and easily, doing these beforehand will reduce their interference with meditation.

\section{Rumination of Aum, Nam Myoho Renge Kyo \& Om Mani Padme Hum}

Chanting is a potent tonic which increases the efficiency of the human organism in a profound manner. The chanting Aum, Nam Myoho Remge Kyo and Om Mani Padme Hum leads to excellent mental and physical health, has positive effect for cardio vascular health lowering blood pressure and increasing efficiency of all the cells and organs in the body. In essence Omkar relaxes and rejuvenates the mind 
increasing concentration and memory therefore the ability to learn.

When chanting mantras like Aum, and Aum Mani Padme Hum, the first pronunciation of " $A$ " creates vibrations, which affect the spinal cord increasing its efficiency. The second pronunciation of " $U$ " creates vibrations in the throat and affects the thyroid glands. The last pronunciation of " $M$ " brings vibrations to the brain centers, as a result of which, the efficiency of the brain increases. Thus the efficiency of the brain increases, ones outlook on life, alleviating depression, bringing an increased level of concentration, increased memory and decreased fatigue, also chanting Om, Nam Myoho Remge Kyo and Om Mani Padme Hum increases oxygen uptake which has a positive effect on health.

In a way chanting Aum, Nam Myoho Remge Kyo and Aum Mani Padme Hum is also a meditation practice when focuses the mind on the breath and the correct pronunciation, when chanting one should focus on the symbols and the significances of the mantras. They can be chanted audibly, whispered or repeated internally with focus breath, symbol, meaning or body awareness. One method of Aum chanting is to inhale fully (relaxed) pronounce A (ah) for 3 seconds, U (ooh as in room)for 5 seconds $M$ for 6 seconds. The $M$ should be pronounced longer then $\mathrm{A}$ and $\mathrm{U}$. A second method of is to repeat Aum 5 times whispering and 10 times internally. This sequence should be repeated for a minimum of 15 minutes. For maximum benefit Aum should be chanted for two $30 \mathrm{~min}$ sessions twice daily. When chanting mantras it should never be forced and one should relax, remaining focused on the vibration created by it. Early morning recitation of Aum, Nam Myoho Remge Kyo and Aum Mani Padme Hum will create an attitude of relaxation while increasing pranic energy for the day. Evening chanting will induce mental calm, physical relaxation and act as a sleep tonic. Therefore these mantras which while rejuvenate the entire human organism and if chanted earnestly will bring profound awakening relief from stress and anxiety.

Effect of Om, Nam Myoho Remge Kyo and Om Mani Padme Hum:

1) Chanting mantras sends out positive vibrations.

2) It also creates positive energy and strengthens the mind.

3) Chanting these mantras evokes the subconscious mind and thus helps you in taking decisions and also brings realizations.

4) Chanting them can heal the mind and the body. It can help you overcome the effects of past harsh events.

5) It can help curtail feelings like depression, anger and jealousy

6) Improved concentration

7) Enhanced creativity

8) Improved vision (physical, mental and spiritual)

9) Brain hemisphere balancing

10) Restoration of equilibrium in the endocrine system by vibrating the pituitary.

11) Relief of sinus congestion and headaches

12) Induction of alpha brainwave activity or deep meditation

13) Increased energy through stimulation of the cerebrospinal fluid (possibly the physical form of kundalini energy)

14) Chakra and aura balancing and cleaning (and corresponding organs and glands)

15) Space clearing

16) Easier access to intuition and higher consciousness

\section{Conclusions}

Hinduism and Buddhism being one of the oldest religions in the world are very much influenced by the music. The mantra whether it is Aum, or Nam Myoho Renge Kyo or Aum Mani Padme Hum, they all have positive effect on one who chants if sung melodiously. When these mantras are chanted, mind is not invaded either by greed, hate or delusion. His mind is quite upright. And by absence of the invasion of greed, etc., his mind faces the subject of meditation with rectitude; then his applied and sustained thoughts occur with a tendency towards the special qualities of the Buddha and happiness arises in him. And then with his mind happy, his bodily disturbance and mental disturbance are tranquillized by tranquility which has happiness as proximate cause. Bodily bliss and mental bliss arises in one.There is lots of positive impact on body as well as on one's health. Therefore we could conclude that music hasvery important impact and rumination on Buddhism though this paper is still in its infancy stage and more work could be done in this area.

\section{REFERENCES}

[1] Noll, R., (1994). The Jung Cult: Origins of a Charismatic Movement. New Jersey: Princeton University Press.

[2] The Dalai Lama (1994). The Way to Freedom: Core Teachings of Tibetan Buddhism. New York: HarperCollins Publishers.

[3] Gunartana, H. (venerable), (1991). Mindfulnessin Plain English. Boston: Wisdom Publications.

[4] Eckhart, Meister, (1996). Meister Eckhart, from Whom God Hid Nothing: Sermons, Writings and Sayings. DavidO'Neil, Ed. Boston: Shambhala.

[5] Feist, J., (1994). Theories of Personality,3rd Ed. New York: Harcourt Brace.

[6] James, W., (1890/1964). The self. In C. Gordon \& K.J. Gergen (Eds.) The self in social interaction (pp 41-49). New York: Wiley.

[7] Paranjpe, A.C. (1995). Is the person missing from theories of personality? In I. Lubek, R. van Hezewijk, G. Pheterson, \& C. Tolman (Eds.), Recent trends in theoretical psychology Vol. 4, pp. 138-143. New York: Springer.

[8] Jung, C.G., (1963). Memories, Dreams, Reflections. Aniela 
Jaff (Ed.). London: Collins and Routledge \& Kegan Paul.

[9] Hall, C.S. and Lindzey, G., (1978). Theories of Personality, 3rd Ed. New York: John.

[10] G, Marc., Hartman, T., (2013). The story of Buddha's Enlightenment. Retrieved

[11] Frye, S. Sutra of the Wise and the Foolish. Library of Tibetan Works and Archives, 1981.
[12] Buswell, R.E. The Princeton Dictionary of Buddhism. Princeton University Press, 2013.

[13] Rcihard, A.., (1961). Buddhism. (pp.207-8). George Braziller, Inc.

[14] Nyanaponika, T. (1962). The Heart of Buddhist Meditation (p82). London Rider and Co.

[15] Shattock, E.H., (1960). An Experiment in Mindfulness (pp 17-19). E.P. Dutton and Co. 